\title{
Clinical, Pathological and Surgical Risk Factors Associated with Craniopharyngioma Recurrence: A Literature Review
}

\author{
James Lubuulwa $\mathbb{B}^{0}$, Zhuang Miao, Shengwen Liu, Juan Chen, Sheng Wang, Wei Jiang, Kai Shu, \\ Ting Lei* \\ Department of Neurosurgery, Tongji Hospital of Tongji Medical College, Huazhong University of Science and Technology, \\ Wuhan, China \\ Email: *tlei@tjh.tjmu.edu.cn
}

How to cite this paper: Lubuulwa, J., Miao, Z., Liu, S.W., Chen, J., Wang, S., Jiang, W., Shu, K. and Lei, T. (2019) Clinical, Pathological and Surgical Risk Factors Associated with Craniopharyngioma Recurrence: A Literature Review. Open Journal of Modern Neurosurgery, 9, 61-77.

https://doi.org/10.4236/ojmn.2019.91008

Received: November 23, 2018

Accepted: January 20, 2019

Published: January 23, 2019

Copyright $\odot 2019$ by authors and Scientific Research Publishing Inc. This work is licensed under the Creative Commons Attribution International License (CC BY 4.0).

http://creativecommons.org/licenses/by/4.0/

(c) $\underset{\mathrm{EY}}{\mathrm{EP}}$ Open Access

\begin{abstract}
Objective: This review article attempts to examine and provide an overview of the risk factors associated with craniopharyngioma recurrence. Methods: A literature review of articles relating to the recurrences of craniopharyngioma and the clinical, molecular prognostic indicators of recurrence and treatment outcomes was performed retrospectively. Results: A total of 107 studies which described specific risk factors related to craniopharyngioma recurrence were identified which included but not limited to 54 retrospective case series, 7 systematic reviews, 21 laboratory reports, 13 case reports and 12 literature reviews. Conclusion: Based on the evidence identified in this review, the risk factors for recurrence in craniopharyngioma management are interrelated in a complex way, and surgery with or without adjuvant radiotherapy is reported to be of long-term benefit, but a disparity in findings suggests no definitive consensus on the risk factors of craniopharyngioma recurrence. More high-quality research is needed.
\end{abstract}

\section{Keywords}

Craniopharyngioma, Recurrence, Risk Factors, Subtotal Resection

\section{Introduction}

Craniopharyngiomas (CPs) are benign tumor epithelial neoplasms of the sellar and parasellar region occurring in all age groups, postulated to arise from pathological alteration of epithelial cell remnants of Rathke's pouch and the craniopharyngeal duct [1]. CPs account for less than $5 \%$ of all intracranial tumors [2] 
and possess a characteristic unpredictable growth pattern and a tendency to invade critical neurovascular structures. Tumor recurrence is a common observation following primary treatment of CP [3] and contributes significantly to the higher mortality and morbidity rates than those with primary CPs [4]. While the management of primary CPs is challenging, the treatment of recurrent CPs is even more exacting and variable [5] [6]. Currently, treatment of recurrent CP involves gross-total resection oriented surgical removal, in combination with or without adjuvant radiotherapy [7] [8], gamma knife surgery [9] [10] [11], stereotactic intracavitary brachytherapy [12], ommaya reservoir placement [13], intratumoral bleomycin [14] and systematic chemotherapy [15]. However, the role of clinical and histopathological features that might be predictors of recurrence/regrowth has not been clearly elucidated in published literature [16].

In the present review, we examined the current literature on the purported risk factors for recurrence, encompassing the epidemiologic, clinical, histopathological and molecular factors, with the aim to provide an overview of the published data regarding their association with $\mathrm{CP}$ recurrence. We also reviewed large retrospective recurrent $\mathrm{CP}$ series and case reports that specifically evaluated the presumed factors for CP recurrence and explore future trends in the treatment.

\section{Methods}

A thorough search of published literature relating to CP recurrence was performed through PubMed and Elsevier-Science Direct databases, mainly utilizing the key word craniopharyngioma, and additional key words such as recurrence, risk factors, subtotal resection and treatment. A literature review of articles relating to the recurrences of craniopharyngioma and the clinical, molecular prognostic indicators of recurrence and treatment outcomes was performed retrospectively. A total of 107 studies which described specific risk factors related to craniopharyngioma recurrence were identified which included but not limited to; 54 retrospective case series, 7 systematic reviews, 21 laboratory reports, 13 case reports and 12 literature reviews.

\section{Discussion}

\subsection{Overview of Potential Risk Factors for CP Recurrence}

\subsubsection{Definition of Recurrence and Regrowth Craniopharyngioma}

Recently, despite the advancement in micro-neurosurgical techniques and neuroimaging modalities to improve preoperative planning and postoperative care, $\mathrm{CP}$ recurrence has remained a well acknowledged conundrum in many treatment centers. There is vast variability in the definition of CP recurrence and regrowth throughout the literature due to the differing methods of assessing and defining recurrence but also variance in the growth potential of the tumor in different individuals. In this paper, we define CP recurrence as evidence of remnant tumor observed on postoperative image studies of the follow-up period 
despite undergoing previous gross total resection (GTR) or subtotal resection (STR) according to the operating neurosurgeon; or despite an initial negative control postoperative follow-up MRI study [5]. In addition, the term regrowth refers to the growth of a known tumor remnant following intentional STR or partial resection in follow-up imaging studies [6].

\subsubsection{Recurrence and Epidemiologic Factors}

Age at the time of treatment is also an important factor, with higher morbidity being assumed more in younger patients than adults, although a number of studies have reported conflicting results with no consensus its association with recurrence rate (RR). According to the literature, exclusive pediatric series have reported recurrence rates ranging from $9 \%$ to $24.5 \%$ [17] [18] [19] [20] [21] Whereas some authors have noted young age [17] [19] as a recurrence risk factor, others adult age [22], most cohorts have not found a significant difference in the recurrence rate between children and adults [4] [6] [16] [23] [24] [25] [26]. Similarly, role of sex as a predictive factor is still under debate; inasmuch as some studies found a significant correlation between the rate of $\mathrm{CP}$ recurrence and the male sex [6] [27], others reported no association with sex whatsoever [16] [19] [25] [26] [28].

\subsubsection{CP Recurrence and Clinical Manifestation}

The biological behavior of CPs varies from patient to patient in that while some remain stable even up to 30 years before symptomatic recurrence [29], others may grow rapidly within an erratic period of time [2] It has been reported that most recurrences appear during the first 5 years following treatment [6] [30]. Similar to primary CPs, the clinical symptoms of RCPs are inconstant, on account of the variable topographical location [31]. CPs of suprasellar region commonly present with headache, visual field defects, and endocrine dysfunctions [32]. A few studies have reported visual symptoms at presentation [24], symptoms of intracranial hypertension at presentation [27] and severe hydrocephalus [17] as significant factors associated with recurrence. However, other cohorts reported no significant differences between patients with primary $\mathrm{CP}$ and RCP in the neurological, endocrinological, visual, or functional symptoms [20] [23] [33] nor the presence of hydrocephalus [19] [25].

\subsubsection{CP Recurrence and Tumor Morphologic Features}

An issue of specific interest is the relevance of tumor morphology in $\mathrm{CP}$ recurrence to which current literature bears inconsistent findings. Tumor size is likely to be a predictive factor because increased recurrence rates have been shown in tumors with a diameter larger than $3 \mathrm{~cm}$ [5] [17] [20] [34] [35]; other studies did not support these findings [27] [36]. Aside from tumor size, other physical attributes such as tumor adherence [37], intrasellar location [28], third ventricle remnants [38] and cystic tumors [34] [39] have been proposed to be clinical predictors of recurrence. In other studies, none of tumor brain invasion [21] [34], tumor extension [19], tumor consistency [26] nor tumor location [19] [22] [25] 
[35] and presence of xanthogranulomatous tissue [16], were found be of significant importance in tumor recurrence. Clinically, the presence of calcifications could suggest a possible involvement with $\mathrm{CP}$ recurrence given the fact that tight adherences to neurostructures have often led to incomplete resection even in some the most skilled hands [40]. On the contrary, Elliot et al. in a cohort of eighty-six pediatric patients showed that the absence or presence of minimal residual calcification does not have an impact on the risk of $\mathrm{CP}$ recurrence after GTR [41].

\subsubsection{CP Recurrence and Radiologic Findings}

Ohmori et al. in a pediatric series of twenty-seven pediatric patients surgically treated for CPs observed a significant low recurrence rate for patients in whom early postoperative MRI reveals complete CP removal [42], in agreement with Mortini's findings [21]. On the other hand, Eldevik et al. [43] studied the radiologic and histologic characteristics of CPs and could not identify any imaging characteristics of tumors that corresponded to a high or low rate of recurrence, as supported by other studies. [23] [44]

\subsubsection{CP Recurrence and Histopathologic or Molecular Features}

Over the past 30 years, studies into the histopathologic nature of CPs have thrown more light into understanding its pathogenesis. Still, the genetic and molecular basis of the recurrence CP is yet to be well elucidated. However, advances in immunohistochemical studies and direct genetic sequencing have attempted to exemplify the molecular pathogenesis of $\mathrm{CP}$ initiation, growth, and recurrence [3]. There are two subtypes of CPs, adamantinomatous (ACP) and papillary (PCP) that may differ clinically and histologically but also share overlapping characteristics. Histologically, ACPs contain nodules of wet keratin, regressive changes like fibrosis, calcifications, old hemorrhages, cholesterol deposits; a mixture of cystic and solid portions, whorl-like structures, ghost cells, intense surrounding gliosis, and profuse rosenthal fiber formation [1] [45] and nucleo-cytoplasmic accumulation of b-catenin [45] [46]. On the other hand, the PCP subtype is distinctly characterized by a solid, papillary growth pattern missing the wet keratin, cystic appearance and regressive elements of the ACP subtype [44].

At the molecular level, extensive studies of whole-exome sequencing data of craniopharyngiomas have revealed that the ACP and PCP subtypes have distinct molecular underpinnings, each driven characteristically by mutual exclusivity of mutations in a single well-established oncogene: CTNNB1 (P-catenin gene) in the ACP form and BRAF in the papillary form as a result of activation of the MAPK pathway [47] [48] [49]. Tena-Suck et al. observed that the presence of whorl-like arrays was associated with recurrence/regrowth of CP [16] which could likely be caused by mutations of the P-catenin gene. Interestingly, several studies have reported no significant differences in recurrence rate and between adamantinomatous type and papillary type [6] [21] [24] [26] [34] [50]. Whilst 
no definitive tumor markers that predict recurrence have not been identified, several recent studies (Table 1) which have attempted to shed more light on some important prognostic factors that may correlate with $\mathrm{CP}$ recurrence have shown that RCPs displayed a significantly higher expression of these postulated biomarkers than primary tumors.

Table 1 summarizes some of the potential biomarkers of $\mathrm{CP}$ recurrence.

Other studies have supported the role of Ep-CAM overexpression in tumor cell proliferation and recurrence in other brain tumors [58] [59]. Conversely, others studied molecular proteins which have been associated with recurrence but have not been found significant include laminin 8 and BCL-2 [51]. Apart from its likely involvement in maintaining the proliferative activity of tumoral cells, increased p53 expression has been purported as a marker of malignancy transformation [60]. Of particular note, Prieto et al. [5] and Tena-Suck [16] reported a positive association of $\mathrm{p} 53$ expression with $\mathrm{CP}$ recurrence, though other studies obviate these findings [60] [61].

The use of proliferation-associated antigen Ki-67 and mitotic index for the histological evaluation of different tumors has been widely reported [5] [18] [62]. On the contrary, other studies found no correlation between Ki-67 and risk of recurrence of CPs [22] [28] [63]. Duo et al. [64] proposed that the very low level of MIB-1-LI in residual tumor remnants negates their role in initiation of recurrence. In disagreement, Hussain et al. [3] purported that rapid recurrence may be a function of the immune response in the tumor microenvironment. Lefranc and colleagues [61] attributed the adhesiveness of CPs to the proximity tissues such as optical chiasm and pituitary stalk to interactions between vitronectin, CP-alpha (2beta1) integrin and collagens, proteins expressed by peritumoral tissue. Furthermore, they demonstrated that galectin- 4 expression was associated with a significant delay in recurrence. In another study, $\mathrm{Xu}$ and colleagues found that minichromosome maintenance protein 6 (MCM6) label

Table 1. Craniopharyngioma recurrence and predictive biomarkers of recurrence.

\begin{tabular}{|c|c|c|c|}
\hline Author, Year & $\begin{array}{l}\text { Number of } \\
\text { cases in study }\end{array}$ & $\begin{array}{l}\text { Predictive } \\
\text { Biomarker }\end{array}$ & Postulated Role in RCP pathogenesis \\
\hline Tena-Suck et al. [51] 2009 & $40 \mathrm{ACPs}$ & Ep-CAM , PTTG-1 & $\begin{array}{l}\text { Ep-CAM expression may be involved with invasiveness and } \\
\text { proliferation; PTGG-1 expression may suggest hypophyseal metaplasia }\end{array}$ \\
\hline Ebrahimi et al. [52] 2013 & 43 & Osteonectin & Marker of tumor invasion and aggressive behavior \\
\hline Gong et al. [53] 2014 & 45 ACPs & CXCL12/CXCR4 & $\begin{array}{l}\text { Play a role in regulating the directional } \\
\text { migration and proliferation of tumor cells }\end{array}$ \\
\hline Stache et al. [54] 2014 & $\begin{array}{l}66 \text { ACPs, } \\
21 \text { PCPs }\end{array}$ & claudin-1(CLDN1) & $\begin{array}{l}\text { Altered distribution of CLDN1 affects } \\
\text { cell mobility and tumor invasiveness }\end{array}$ \\
\hline Samis et al. [55] 2016 & 23 & miR-132 & $\begin{array}{c}\text { Downregulation of miR-132 appears to be a marker of aggressiveness } \\
\text { and also plays a role in epithelial-mesenchymal transition }\end{array}$ \\
\hline Li et al. [56] 2016 & 50 & FABP5/CRABPII & $\begin{array}{l}\text { FABP5/CRABPII determines cellular response to physiological } \\
\text { level of retinoic acid which may be involved in tumor cell apoptosis }\end{array}$ \\
\hline Wang et al. [57] 2017 & 65 ACPs & AnnexinA2 (AnxA2) & affects cell mobility and tumor progression \\
\hline
\end{tabular}


index (LI) was significantly higher in primary CPs than in RCPs [65]. Whether angiogenesis-related factors play a part in CP recurrence is still a matter of contention. In line with this observation, Sun et al. compared the expression of angiogenesis-related factors in 4 recurrent and 6 nonrecurrent tumors, they found that expression of PDGFR-alpha and FGF-2 were significantly higher for recurrent tumors $(P=0.02$ and $P=0.01)$, thus suggesting that selective PDGFR-alpha blockers may offer a novel therapeutic option for CP treatment [66], although they no significant correlation with VEGF, in parallel with $\mathrm{Xu}$ et al. findings [65], but in disagreement, Agozzino [22] found a significantly higher VEGF expression in recurrences than in primary $\mathrm{CP}$.

\subsubsection{CP Recurrence and Malignancy and Ectopic Occurrence.}

Despite their reportedly benign nature, a few cases of malignant transformation of primary CP diagnosis on recurrence [67] [68] [69] have been reported but the exact pathogenesis and the biological behavior of malignant change in recurrent $\mathrm{CP}$ are not well elucidated in although a possible causative association with radiation therapy has been postulated [68] [70]. Ectopic recurrence of CP after primary surgical management is no longer a rare phenomenon as several reports have been documented [71] [72] [73] [74] with a widely accepted pathophysiological hypothesis which evolves around tumor seeding occurs either along the surgical route, or at a distal location in the subarachnoid space [71] [73].

\subsection{CP Recurrence and Treatment of Recurrent Craniopharyngioma}

\subsubsection{CP Recurrence and Surgical Management}

The optimal management of recurrent craniopharyngioma (RCP) is still disputable [75]. However, several authors have stressed that radical surgery should be the first therapeutic option for RCP with acceptable morbidity and mortality risks similar to that of primary tumors [6] [18] [20] [76] [77] [78]. Conversely, others have reiterated that secondary surgery for RCP is associated with a low cure rate and a high risk of complications [19] [37] [75]. In addition, recurrence rates following radical tumor resection vary widely and have been reported as $9 \%$ to $65 \%$ [19] [21] [23] while others noted that the incidence of recurrence did not differ significantly with radicality at surgery [4]. In general, several authors have echoed that surgical treatment for RCP is considered more challenging than primary surgery due to scarring, absence of gliosis reaction in RCP, tight adherences and morphological changes due to irradiation [2] [37] [75]. Most published literature has consistently reported residual tumor and the extent of resection as the strongest predictive factor for CP recurrence [6] [16] [17] [20] [25] [34] [37] [63]. In contrast, other studies have downplayed the role of residual CP as a predictive of recurrence [4] [40] [64].

Accordingly, due to the variable location of CPs or RCPs in proximity with neurostructures, some surgeons have advocated for intentional subtotal or partial removal for reasons not limited to; hypothalamic adherence of $\mathrm{CP}$ which is 
associated with postoperative morbidity and mortality [36]; an inadequate view of the tumor due to large tumor extensions and inappropriate surgical approach; presence of major calcifications [37] which poses a risk of damage to the hypothalamus and the optic chiasm [37] [77]; firm adherence of the tumor capsule to relatively large perforating vessels or to large basal arteries as it is safer to leave minor residual portions of tumor in anticipation of vascular damage [32] [79]. Prieto demonstrated that in an effort to preserve the hypothalamus, the CP remnants may lead to erratic tumor recurrence [38], whereas studies by Li et al. [80] mentioned otherwise. It has been noted significant number of patients with residual tumors remain stable for a long time [36]. Similarly, Hoffman et al. recommended that radical surgery is not an appropriate treatment strategy in patients with hypothalamic involvement [45]. In a recent study, Clark et al. reviewed a total of 109 studies describing the extent of resection resulting in a cohort of 531CP patients and 377 recurrences. They found no difference in the progression-free survival (PFS) of 1 year ( $89 \%$ vs $84 \%$ ) or 5 -year (77\% vs $73 \%$ ) between the groups who underwent GTR and STR combined with radiation. Their results suggest that STR + XRT of pediatric CP is associated with similar rates of tumor control as GTR [7]. These findings were similar to those of Schoenfeld et al. [26] and Yang [81] and colleagues. What remains unclear is whether the preservation of pituitary stalk at resection represents a recurrence prognostic factor because some studies have demonstrated a correlation with recurrence [82] [83] whereas other studies reported no significant association with CP recurrence [33] [83]. In some population of CP patients, although Growth hormone replacement therapy (GHRT) may pose a concern for stimulating tumor regrowth, several studies have demonstrated that long-term GHRT is not associated with risk of CP recurrence [84] [85] [86].

Throughout literature, CPs and RCPs have been widely reported to present in the variable locations [31]. On these grounds, several surgical approaches in recurrent CP series including transsphenoidal, subfrontal, trans-lamina terminalis, subtemporal and transcallosal approach [2] [6] [75] [78] [87] [88] have been advocated with the effort to reduce morbidity and mortality risks, although the optimum surgical approach is still debatable. In a recent publication, Morisako et al. attempted to devise an anatomical subclassification of CPs for achieving aggressive surgery [89]. In a similar vein, Prieto et al. [5] stressed that evasion of hypothalamic injury should be the primary goal in any surgical planning, including the choice of approach and preplanned extent of removal. A few authors have strongly recommended the use of endonasal route [2] [90] for recurrent tumors especially patients in whom the initial surgery was transcranial, asserting the advantage it offers of facing the tumor upon dural opening without brain retraction while optimizing visualization of the relevant anatomy via a direct surgical trajectory.

\subsubsection{CP Recurrence and Radiotherapy}

The role of adjuvant radiotherapy (RT) in the management of RCP is well do- 
cumented in literature with numerous studies showing lower recurrence rates after GTR or STR [2] [8] [18] [26] [43]. In contrast, other studies have reported that the incidence of recurrence did not differ significantly with respect to postoperative radiotherapy [4] [16] [91]. In a review of pediatric CP surgical series, Tomita et al. demonstrated that RT was effective for recurrent tumors and should be considered being the primary treatment for recurrences or difficult tumors, which are not amenable to total resections [19]. The optimum timing of RT for RCP is still controversial. Fisher et al. observed that short times to recurrence may result from the tendency to delay radiotherapy [40]. Additionally, Elliot et al. the authors observed that withholding irradiation or other adjuvant therapy in the setting of minimal residual calcification without enhancing tumor [41].

\subsubsection{CP Recurrence and Gamma Knife Surgery (GKS)}

The efficacy of GKS as a valuable adjuvant treatment modality for RCP has been well documented [11] [91] [92] despite its limitation to small size tumors $(<3$ $\mathrm{cm}$ ). A study by Park et al. [9] showed that STR followed by GKS results in a lower recurrence rate than neuroendoscopy-GKS and GKS alone group much as the latter provided better preservation of endocrine function. Others studies have proposed CP histological subtype [93] intratumoral homogeneous irradiation using multiple isocenters [94], distance from the tumor to the optic nerves, and tumor radiosensitivity [10] as prognostic factors that favor successful treatment outcome in RCP. In a large cohort of one hundred CP cases, Kobayashi et al. [95] demonstrated that tumor diameter and radiation dose were the only the significant prognostic factors related to recurrence of CP.

\subsubsection{CP Recurrence and Other Conventional Treatment Modalities}

1) Intracavitary Brachytherapy: Recent studies investigating the efficacy of intracavitary brachytherapy have shown that inasmuch as it may offer a treatment option for cystic CPs, its use is limited by the fact that it does not limit growth of solid tumor parts or deter formation of new CP cysts [12] [96].

2) Intracystic Bleomycin Therapy: Hader et al. [97] reported significant tumor control with use of intratumoral bleomycin for cystic CPs, while avoiding potentially harmful surgical or radiotherapy related risks in the pediatric population. Reported complications related with this treatment include bleomycin leakage and toxicity, vasculopathy [98] and fatal toxic effects [99]. However, importantly, Zhang [14] and colleagues argued the rational use of intracystic bleomycin due to lack of RCTs, quasi-randomised trials or CCTs of the treatment of cystic CPs in children.

3) Pegylated interferon-a-2 $b$ : Yet another systematic conventional therapy [100] reportedly used in treatment of cystic recurrent CPs and some studies have shown its efficacy in children [101], however, its toxicity and optimum dosage obviate its importance and suggestively large series are necessary to establish its long term benefit. 


\subsection{Future Perspectives}

The modern era has witnessed a surge in advancement of the diagnostic techniques, imaging modalities, immunohistochemical and genetic studies aimed at understanding molecular pathogenesis of CPs and RCPs. In effect, trials of specific therapeutics for CPs have been explored in various in vivo studies and possibly RCTs. Simon et al. reported part of the successful use of , a BRAF inhibitor vemurafenib with excellent tumor response for treatment of PCP [102]. Li [103] and colleagues suggested all-trans retinoic acid (ATRA) as a potential therapeutic agent for $\mathrm{CP}$ chemotherapy given its efficacy at pharmacological level induced craniopharyngioma cell apoptosis via increasing FABP5/CRABPII ratio and inhibiting NF-kappaB signaling pathway (107). Similarly, Sun et al. [66] suggested the possible use of selective PDGFR-a blockers for CPs given the higher expression of PDGFR-a and FGF-2 in RCPs versus primary CPs as reported in a recent study. In a recent study, Gump [104] and associates reported several notable significantly overexpressed genes of kinase inhibitors and EGFR pathways in ACPs comparable to normal brain tissue, pediatric brain tumors, normal pituitary, and pituitary tumors, suggesting their potential role as new pharmacological agents for pediatric $\mathrm{CP}$ treatment. In another recent study, Uto et al. [105] described the potential use of Non-coplanar volumetric-modulated arc therapy (VMAT) in effectively reducing radiation doses to the bilateral hippocampus, comparison to dynamic conformal arc therapy (DCAT).

In summary, randomized control trials (RCTs) and more comprehensive studies targeting genomic modifiers influencing cell survival, angiogenesis, invasion, and recurrence are necessary. These studies in reality may take many years before being successfully rendered expedient for clinical applications but will guide the development of genetically engineered animal models that more accurately epitomize human CPs, providing a remarkable ability to develop and ratify optimal therapeutic regimens for individuals with recurrent CPs. However, even though RCTs are the highest level of evidence, data from non-RCT cohorts offers valuable information given the clinical rarity and impact of CPs to constitute large cohorts.

\section{Conclusion}

Based on the evidence identified in this review, the risk factors for recurrence in craniopharyngioma are interrelated in a complex way, and surgery with or without adjuvant radiotherapy is reported to be of long-term benefit, but a disparity in findings suggests no definitive consensus on the risk factors of craniopharyngioma recurrence. More high-quality research is needed.

\section{Conflicts of Interest}

The authors report no conflict of interest concerning the materials or methods used in this study or the findings specified in this paper. 


\section{References}

[1] Muller, H.L. (2014) Craniopharyngioma. Endocrine Reviews, 35, 513-543. https://doi.org/10.1210/er.2013-1115

[2] Turel, M.K., et al. (2016) Management and Outcome of Recurrent Adult Craniopharyngiomas: An Analysis of 42 Cases with Long-Term Follow-Up. Neurosurgical Focus, 41, E11. https://doi.org/10.3171/2016.9.FOCUS16315

[3] Hussain, I., et al. (2013) Molecular Oncogenesis of Craniopharyngioma: Current and Future Strategies for the Development of Targeted Therapies. Journal of Neurosurgery, 119, 106-112. https://doi.org/10.3171/2013.3.JNS122214

[4] Bulow, B., et al. (1998) Postoperative Prognosis in Craniopharyngioma with Respect to Cardiovascular Mortality, Survival, and Tumor Recurrence. The Journal of Clinical Endocrinology \& Metabolism, 83, 3897-3904.

https://doi.org/10.1210/jc.83.11.3897

[5] Prieto, R., et al. (2013) Predictive Factors for Craniopharyngioma Recurrence: A Systematic Review and Illustrative Case Report of a Rapid Recurrence. World Neurosurgery, 79, 733-749. https://doi.org/10.1016/j.wneu.2012.07.033

[6] Minamida, Y., et al. (2005) Surgical Management of the Recurrence and Regrowth of craNiopharyngiomas. Journal of Neurosurgery, 103, 224-232. https://doi.org/10.3171/jns.2005.103.2.0224

[7] Clark, A.J., et al. (2013) A Systematic Review of the Results of Surgery and Radiotherapy on Tumor Control for Pediatric Craniopharyngioma. Child s Nervous System, 29, 231-238. https://doi.org/10.1007/s00381-012-1926-2

[8] Rao, Y.J., et al. (2016) Patterns of Care and Treatment Outcomes of Patients with Craniopharyngioma in the National Cancer Database. Journal of Neurosurgery, 132, 109-117.

[9] Park, Y.S., et al. (2011) Recurrence Rates after Neuroendoscopic Fenestration and Gamma Knife Surgery in Comparison with Subtotal Resection and Gamma Knife Surgery for the Treatment of Cystic Craniopharyngiomas. Journal of Neurosurgery, 114, 1360-1368. https://doi.org/10.3171/2009.9.JNS09301

[10] Kobayashi, T., et al. (2012) Prognostic Factors for Tumor Recurrence after Gamma Knife Radiosurgery of Partially Resected and Recurrent Craniopharyngiomas. Nagoya Journal of Medical Science, 74, 141-147.

[11] Lee, C.C., et al. (2014) Gamma Knife Surgery for Craniopharyngioma: Report on a 20-Year Experience. Journal of Neurosurgery, 121, 167-178. https://doi.org/10.3171/2014.8.GKS141411

[12] Maarouf, M., et al. (2016) Stereotactic Intracavitary Brachytherapy with P-32 for Cystic Craniopharyngiomas in Children. Strahlentherapie und Onkologie, 192, 157-165. https://doi.org/10.1007/s00066-015-0910-7

[13] Shukla, D. (2015) Transcortical Transventricular Endoscopic Approach and Ommaya Reservoir Placement for Cystic Craniopharyngioma. Pediatric Neurosurgery, 50, 291-294. https://doi.org/10.1159/000433605

[14] Zhang, S., Fang, Y., Cai, B.W., Xu, J.G. and You, C. (2016) Intracystic Bleomycin for Cystic Craniopharyngiomas in Children. Cochrane Database of Systematic Reviews, No. 7, CD008890. https://doi.org/10.1002/14651858.CD008890.pub4

[15] Lippens, R.J., et al. (1998) Chemotherapy with Adriamycin (Doxorubicin) and CCNU (Lomustine) in Four Children with Recurrent Craniopharyngioma. European Journal of Paediatric Neurology, 2, 263-268. https://doi.org/10.1016/S1090-3798(98)80040-8 
[16] Tena-Suck, M.L., et al. (2006) Clinico-Pathological and Immunohistochemical Characteristics Associated to Recurrence/Regrowth of Craniopharyngiomas. Clinical Neurology and Neurosurgery, 108, 661-669. https://doi.org/10.1016/j.clineuro.2006.01.007

[17] De Vile, C.J., et al. (1996) Management of Childhood Craniopharyngioma: Can the Morbidity of Radical Surgery Be Predicted? Journal of Neurosurgery, 85, 73-81. https://doi.org/10.3171/jns.1996.85.1.0073

[18] Caldarelli, M., di Rocco, C., Papacci, F. and Colosimo Jr., C. (1998) Management of Recurrent Craniopharyngioma. Acta Neurochirurgica, 140, 447-454. https://doi.org/10.1007/s007010050123

[19] Tomita, T. and Bowman, R.M. (2005) Craniopharyngiomas in Children: Surgical Experience at Children's Memorial Hospital. Child s Nervous System, 21, 729-746. https://doi.org/10.1007/s00381-005-1202-9

[20] Elliott, R.E., et al. (2010) Efficacy and Safety of Radical Resection of Primary and Recurrent Craniopharyngiomas in 86 Children. Journal of Neurosurgery. Pediatrics, 5, 30-48. https://doi.org/10.3171/2009.7.PEDS09215

[21] Mortini, P., et al. (2011) Neurosurgical Treatment of Craniopharyngioma in Adults and Children: Early and Long-Term Results in a Large Case Series. Journal of Neurosurgery, 114, 1350-1359. https://doi.org/10.3171/2010.11.JNS10670

[22] Agozzino, L., et al. (2006) Morphological and Ultrastructural Findings of Prognostic Impact in Craniopharyngiomas. Ultrastructural Pathology, 30, 143-150. https://doi.org/10.1080/01913120500408018

[23] Liubinas, S.V., Munshey, A.S. and Kaye, A.H. (2011) Management of Recurrent Craniopharyngioma. Journal of Clinical Neuroscience, 18, 451-457. https://doi.org/10.1016/j.jocn.2010.10.004

[24] Duff, J., et al. (2000) Long-Term Outcomes for Surgically Resected Craniopharyngiomas. Neurosurgery, 46, 291-302. https://doi.org/10.1097/00006123-200002000-00007

[25] Karavitaki, N., et al. (2005) Craniopharyngiomas in Children and Adults: Systematic Analysis of 121 Cases with Long-Term Follow-Up. Clinical Endocrinology, 62, 397-409. https://doi.org/10.1111/j.1365-2265.2005.02231.x

[26] Schoenfeld, A., et al. (2012) The Superiority of Conservative Resection and Adjuvant Radiation for Craniopharyngiomas. Journal of Neuro-Oncology, 108, 133-139. https://doi.org/10.1007/s11060-012-0806-7

[27] Gautier, A., et al. (2012) Markers of Recurrence and Long-Term Morbidity in Craniopharyngioma: A Systematic Analysis of 171 Patients. The Journal of Clinical Endocrinology \& Metabolism, 97, 1258-1267. https://doi.org/10.1210/jc.2011-2817

[28] Kim, S.K., et al. (2001) Radical Excision of Pediatric Craniopharyngioma: Recurrence Pattern and Prognostic Factors. Child s Nervous System, 17, 531-536. https://doi.org/10.1007/s003810100458

[29] Clark, S.W., Kenning, T.J. and Evans, J.J. (2015) Recurrent Ectopic Craniopharyngioma in the Sylvian Fissure Thirty Years after Resection through a Pterional Approach: A Case Report and Review of the Literature. Nagoya Journal of Medical Science, 77, 297-306.

[30] Yasargil, M.G., et al. (1990) Total Removal of Craniopharyngiomas. Approaches and Long-Term Results in 144 Patients. Journal of Neurosurgery, 73, 3-11.

[31] Lubuulwa, J. and Lei, T. (2016) Pathological and Topographical Classification of Craniopharyngiomas: A Literature Review. Journal of Neurological Surgery Re- 
ports, 77, e121-e127. https://doi.org/10.1055/s-0036-1588060

[32] Gerganov, V., Metwali, H., Samii, A., Fahlbusch, R. and Samii, M. (2014) Microsurgical Resection of Extensive Craniopharyngiomas Using a Frontolateral Approach: Operative Technique and Outcome. Journal of Neurosurgery, 120, 559-570. https://doi.org/10.3171/2013.9.JNS122133

[33] Lee, E.J., et al. (2015) Is the Complete Resection of Craniopharyngiomas in Adults Feasible Considering Both the Oncologic and Functional Outcomes? Journal of Korean Neurosurgical Society, 58, 432-441. https://doi.org/10.3340/jkns.2015.58.5.432

[34] Gupta, D.K., Ojha, B.K., Sarkar, C., Mahapatra, A.K. and Mehta, V.S. (2006) Recurrence in Craniopharyngiomas: Analysis of Clinical and Histological Features. Journal of Clinical Neuroscience, 13, 438-442. https://doi.org/10.1016/j.jocn.2005.05.013

[35] Shi, X.E., Wu, B., Fan, T., Zhou, Z.-Q. and Zhang, Y.-L. (2008) Craniopharyngioma: Surgical Experience of 309 Cases in China. Clinical Neurology and Neurosurgery, 110, 151-159. https://doi.org/10.1016/j.clineuro.2007.10.013

[36] Puget, S., et al. (2007) Pediatric Craniopharyngiomas: Classification and Treatment According to the Degree of Hypothalamic Involvement. Journal of Neurosurgery, $106,3-12$.

[37] Fahlbusch, R., Honegger, J., Paulus, W., Huk, W. and Buchfelder, M. (1999) Surgical Treatment of Craniopharyngiomas: Experience with 168 Patients. Journal of Neurosurgery, 90, 237-250. https://doi.org/10.3171/jns.1999.90.2.0237

[38] Prieto, R., Castro-Dufourny, I., Carrasco, R., Barrios, L. and Pascual, J.M. (2016) Craniopharyngioma Recurrence: The Impact of Tumor Topography. Journal of Neurosurgery, 125, 1043-1049. https://doi.org/10.3171/2016.3.JNS16630

[39] Pettorini, B.L., et al. (2010) The Role of Inflammation in the Genesis of the Cystic Component of Craniopharyngiomas. Child s Nervous System, 26, 1779-1784. https://doi.org/10.1007/s00381-010-1245-4

[40] Fisher, P.G., et al. (1998) Outcomes and Failure Patterns in Childhood Craniopharyngiomas. Child s Nervous System, 14, 558-563. https://doi.org/10.1007/s003810050272

[41] Elliott, R.E., Moshel, Y.A. and Wisoff, J.H. (2009) Minimal Residual Calcification and Recurrence after Gross-Total Resection of Craniopharyngioma in Children. Journal of Neurosurgery. Pediatrics, 3, 276-283. https://doi.org/10.3171/2009.1.PEDS08335

[42] Ohmori, K., Collins, J. and Fukushima, T. (2007) Craniopharyngiomas in Children. Pediatric Neurosurgery, 43, 265-278. https://doi.org/10.1159/000103306

[43] Eldevik, O.P., et al. (1996) Craniopharyngioma: Radiologic and Histologic Findings and Recurrence. American Journal of Neuroradiology, 17, 1427-1439.

[44] Crotty, T.B., et al. (1995) Papillary Craniopharyngioma: A Clinicopathological Study of 48 Cases. Journal of Neurosurgery, 83, 206-214. https://doi.org/10.3171/jns.1995.83.2.0206

[45] Hoffmann, A., et al. (2014) Childhood Craniopharyngioma-Changes of Treatment Strategies in the Trials Kraniopharyngeom 2000/2007. Klinische Pädiatrie, 226, 161-168. https://doi.org/10.1055/s-0034-1368785

[46] Andoniadou, C.L., et al. (2012) Identification of Novel Pathways Involved in the Pathogenesis of Human Adamantinomatous Craniopharyngioma. Acta Neuropathologica, 124, 259-271. https://doi.org/10.1007/s00401-012-0957-9

[47] Brastianos, P.K., et al. (2014) Exome Sequencing Identifies BRAF Mutations in Papillary Craniopharyngiomas. Nature Genetics, 46, 161-165. 
https://doi.org/10.1038/ng.2868

[48] Martinez-Barbera, J.P. (2015) 60 Years of Neuroendocrinology: Biology of Human Craniopharyngioma: Lessons from Mouse Models. Journal of Endocrinology, 226, T161-T172. https://doi.org/10.1530/JOE-15-0145

[49] Larkin, S.J. and Ansorge, O. (2013) Pathology and Pathogenesis of Craniopharyngiomas. Pituitary, 16, 9-17. https://doi.org/10.1007/s11102-012-0418-4

[50] Lee, I.H., et al. (2016) Craniopharyngiomas: Radiological Differentiation of Two Types. Journal of Korean Neurosurgical Society, 59, 466-470. https://doi.org/10.3340/jkns.2016.59.5.466

[51] Tena-Suck, M.L., Ortiz-Plata, A., Galán, F. and Sánchez, A. (2009) Expression of Epithelial Cell Adhesion Molecule and Pituitary Tumor Transforming Gene in Adamantinomatous Craniopharyngioma and Its Correlation with Recurrence of the Tumor. Annals of Diagnostic Pathology, 13, 82-88. https://doi.org/10.1016/j.anndiagpath.2008.12.004

[52] Ebrahimi, A., Honegger, J., Schluesener, H. and Schittenhelm, J. (2013) Osteonectin Expression in Surrounding Stroma of Craniopharyngiomas: Association with Recurrence Rate and Brain Infiltration. International Journal of Surgical Pathology, 21, 591-598. https://doi.org/10.1177/1066896913486695

[53] Gong, J., et al. (2014) High Expression Levels of CXCL12 and CXCR4 Predict Recurrence of Adamanti-Nomatous Craniopharyngiomas in Children. Cancer Biomarkers, 14, 241-251. https://doi.org/10.3233/CBM-140397

[54] Stache, C., et al. (2014) Tight Junction Protein Claudin-1 Is Differentially Expressed in Craniopharyngioma Subtypes and Indicates Invasive Tumor Growth. Neuro-Oncology, 16, 256-264. https://doi.org/10.1093/neuonc/not195

[55] Samis, J., et al. (2016) Extensive miRNA Expression Analysis in Craniopharyngiomas. Child s Nervous System, 32, 1617-1624.

https://doi.org/10.1007/s00381-016-3131-1

[56] Li, Q., et al. (2016) High FABP5 versus CRABPII Expression Ratio in Recurrent Craniopharyngiomas: Implications for Future Treatment. World Neurosurgery, 94, 197-205. https://doi.org/10.1016/j.wneu.2016.05.063

[57] Wang, Y., et al. (2017) Clinical and Prognostic Role of Annexin A2 in Adamantinomatous Craniopharyngioma. Journal of Neuro-Oncology, 131, 21-29. https://doi.org/10.1007/s11060-016-2273-z

[58] Carpenter, G. and Red Brewer, M. (2009) EpCAM: Another Surface-to-Nucleus Missile. Cancer Cell, 15, 165-166. https://doi.org/10.1016/j.ccr.2009.02.005

[59] Chen, X., et al. (2014) Overexpression of EpCAM and Trop2 in Pituitary Adenomas. International Journal of Clinical and Experimental Pathology, 7, 7907-7914.

[60] Ishida, M., et al. (2010) Malignant Transformation in Craniopharyngioma after Radiation Therapy: A Case Report and Review of the Literature. Clinical Neuropathology, 29, 2-8. https://doi.org/10.5414/NPP29002

[61] Lefranc, F., et al. (2005) Monitoring the Expression Profiles of Integrins and Adhesion/Growth-Regulatory Galectins in Adamantinomatous Craniopharyngiomas: Their Ability to Regulate Tumor Adhesiveness to Surrounding Tissue and Their Contribution to Prognosis. Neurosurgery, 56, 763-776. https://doi.org/10.1227/01.NEU.0000156788.44397.B4

[62] Izumoto, S., et al. (2005) Immunohistochemical Detection of Female Sex Hormone Receptors in Craniopharyngiomas: Correlation with Clinical and Histologic Features. Surgical Neurology, 63, 520-525. https://doi.org/10.1016/j.surneu.2004.08.094 
[63] Losa, M., et al. (2004) Correlation between Clinical Characteristics and Proliferative Activity in Patients with Craniopharyngioma. Journal of Neurology, Neurosurgery, and Psychiatry, 75, 889-892. https://doi.org/10.1136/jnnp.2003.012781

[64] Duo, D., et al. (2003) MIB-1 Immunoreactivity in Craniopharyngiomas: A Clinico-Pathological Analysis. Clinical Neuropathology, 22, 229-234.

[65] Xu, J., Zhang, S., You, C., Huang, S., Cai, B. and Wang, X. (2007) Expression of Human MCM6 and DNA Topo II Alpha in Craniopharyngiomas and Its Correlation with Recurrence of the Tumor. Journal of Neuro-Oncology, 83, 183-189. https://doi.org/10.1007/s11060-006-9284-0

[66] Sun, H.I., et al. (2010) Expression of Angiogenic Factors in Craniopharyngiomas: Implications for Tumor Recurrence. Neurosurgery, 66, 744-750. https://doi.org/10.1227/01.NEU.0000367553.65099.14

[67] Gao, S., Shi, X., Wang, Y., Qian, H. and Liu, C. (2011) Malignant Transformation of Craniopharyngioma: Case Report and Review of the Literature. Journal of Neuro-Oncology, 103, 719-725. https://doi.org/10.1007/s11060-010-0407-2

[68] Kristopaitis, T., et al. (2000) Malignant Craniopharyngioma. Archives of Pathology \& Laboratory Medicine, 124, 1356-1360.

[69] Wang, W., et al. (2015) Malignant Transformation of Craniopharyngioma with Detailed Follow-Up. Neuropathology, 35, 50-55. https://doi.org/10.1111/neup.12142

[70] Aquilina, K., et al. (2010) Malignant Transformation of Irradiated Craniopharyngioma in Children: Report of 2 Cases. Journal of Neurosurgery: Pediatrics, 5, 155-161. https://doi.org/10.3171/2009.9.PEDS09257

[71] Bikmaz, K., et al. (2009) Ectopic Recurrence of Craniopharyngiomas: Case Report. Neurosurgery, 64, E382-E383. https://doi.org/10.1227/01.NEU.0000337078.60998.98

[72] Goncalves, C.B., et al. (2014) Subgaleal Recurrence of Craniopharyngioma of Rapid Growing Pattern. Pituitary, 17, 214-219. https://doi.org/10.1007/s11102-013-0490-4

[73] Romani, R., et al. (2010) Ectopic Recurrence of Craniopharyngioma along the Surgical Route: Case Report and Literature Review. Acta Neurochirurgica, 152, 297-302. https://doi.org/10.1007/s00701-009-0415-1

[74] Schmalisch, K., Beschorner, R., Psaras, T. and Honegger, J. (2010) Postoperative Intracranial Seeding of Craniopharyngiomas-Report of Three Cases and Review of the Literature. Acta Neurochirurgica, 152, 313-319.

https://doi.org/10.1007/s00701-009-0538-4

[75] Kalapurakal, J.A., et al. (2000) Clinical Outcome in Children with Recurrent Craniopharyngioma after Primary Surgery. The Cancer Journal, 6, 388-393.

[76] Jo, K.W., et al. (2012) Treatment Outcomes of Pediatric Craniopharyngioma: A 15-Year Retrospective Review of 35 Cases. Journal of Korean Neurosurgical Society, 52, 37-41. https://doi.org/10.3340/jkns.2012.52.1.37

[77] Chamoun, R. and Couldwell, W.T. (2013) Transcortical-Transforaminal Microscopic Approach for Purely Intraventricular Craniopharyngioma. Neurosurgical Focus, 34, Video 4.

[78] Bao, Y., Qiu, B., Qi, S., Pan, J., Lu, Y. and Peng, J. (2016) Influence of Previous Treatments on Repeat Surgery for Recurrent Craniopharyngiomas in Children. Child s Nervous System, 32, 485-491. https://doi.org/10.1007/s00381-015-3003-0

[79] Yano, S., et al. (2015) A Flexible Endoscope-Assisted Interhemispheric Transcallosal Approach through the Contralateral Ventricle for the Removal of a Third Ventricle Craniopharyngioma: A Technical Report. Surgical Neurology International, 6, 
S113-S116. https://doi.org/10.4103/2152-7806.153653

[80] Li, K., Lu, X., Yang, N., Zheng, J., Huang, B. and Li, L. (2015) Association of Pituitary Stalk Management with Endocrine Outcomes and Recurrence in Microsurgery of Craniopharyngiomas: A Meta-Analysis. Clinical Neurology and Neurosurgery, 136, 20-24. https://doi.org/10.1016/j.clineuro.2015.05.019

[81] Yang, I., et al. (2010) Craniopharyngioma: A Comparison of Tumor Control with Various Treatment Strategies. Neurosurgical Focus, 28, E5. https://doi.org/10.3171/2010.1.FOCUS09307

[82] Yamada, S., et al. (2010) Surgical Outcome in 90 Patients with Craniopharyngioma: An Evaluation of Transsphenoidal Surgery. World Neurosurgery, 74, 320-330. https://doi.org/10.1016/j.wneu.2010.06.014

[83] Jung, T.Y., Jung, S., Moon, K.-S., Kim, I.-Y., Kang, S.-S. and Kim, J.-H. (2010) Endocrinological Outcomes of Pediatric Craniopharyngiomas with Anatomical Pituitary Stalk Preservation: Preliminary Study. Pediatric Neurosurgery, 46, 205-212. https://doi.org/10.1159/000318426

[84] Olsson, D.S., et al. (2012) Tumour Recurrence and Enlargement in Patients with Craniopharyngioma with and without GH Replacement Therapy during More than 10 Years of Follow-Up. European Journal of Endocrinology, 166, 1061-1068. https://doi.org/10.1530/EJE-12-0077

[85] Smith, T.R., Cote, D.J., Jane Jr., J.A. and Laws Jr., E.R. (2016) Physiological Growth Hormone Replacement and Rate of Recurrence of Craniopharyngioma: The Genentech National Cooperative Growth Study. Journal of Neurosurgery. Pediatrics, 18, 408-412. https://doi.org/10.3171/2016.4.PEDS16112

[86] Karavitaki, N., et al. (2006) GH Replacement Does Not Increase the Risk of Recurrence in Patients with Craniopharyngioma. Clinical Endocrinology, 64, 556-560. https://doi.org/10.1111/j.1365-2265.2006.02508.x

[87] Qi, S.T., Pan, J. and Zhang, J.L. (2003) Clinical Feature and Surgical Treatment of Recurrent Craniopharyngiomas. Academic Journal of the First Medical College of PLA, 23, 1078-1081.

[88] Steno, J., Bízik, I., Šteňo, A. and Matejčík, V. (2014) Recurrent Craniopharyngiomas in Children and Adults: Long-Term Recurrence Rate and Management. Acta Neurochirurgica, 156, 113-122. https://doi.org/10.1007/s00701-013-1938-z

[89] Morisako, H., et al. (2016) Aggressive Surgery Based on an Anatomical Subclassification of Craniopharyngiomas. Neurosurgical Focus, 41, E10. https://doi.org/10.3171/2016.9.FOCUS16211

[90] Cavallo, L.M., et al. (2009) Extended Endoscopic Endonasal Transsphenoidal Approach for Residual or Recurrent Craniopharyngiomas. Journal of Neurosurgery, 111, 578-589. https://doi.org/10.3171/2009.2.JNS081026

[91] Klimo, P., Venable, G.T., Boop, F.A. and Merchant, T.E. (2015) Recurrent Craniopharyngioma after Conformal Radiation in Children and the Burden of Treatment. Journal of Neurosurgery: Pediatrics, 15, 499-505. https://doi.org/10.3171/2014.10.PEDS14384

[92] Xu, Z., Yen, C.-P., Schlesinger, D. and Sheehan, J. (2011) Outcomes of Gamma Knife Surgery for Craniopharyngiomas. Journal of Neuro-Oncology, 104, 305-313. https://doi.org/10.1007/s11060-010-0494-0

[93] Inoue, H.K., et al. (1994) Radiosensitive Craniopharyngiomas: The Role of Radiosurgery. Acta Neurochirurgica Supplement, 62, 43-46. https://doi.org/10.1007/978-3-7091-9371-6_9

[94] Amendola, B.E., Wolf, A., Coy, S.R. and Amendola, M.A. (2003) Role of Radiosur- 
gery in Craniopharyngiomas: A Preliminary Report. Medical and Pediatric Oncology, 41, 123-127. https://doi.org/10.1002/mpo.10364

[95] Kobayashi, T., Kida, Y., Mori, Y. and Hasegawa, T. (2005) Long-Term Results of Gamma Knife Surgery for the Treatment of Craniopharyngioma in 98 Consecutive Cases. Journal of Neurosurgery, 103, 482-488. https://doi.org/10.3171/ped.2005.103.6.0482

[96] Kickingereder, P., et al. (2012) Intracavitary Brachytherapy Using Stereotactically Applied Phosphorus-32 Colloid for Treatment of Cystic Craniopharyngiomas in 53 Patients. Journal of Neuro-Oncology, 109, 365-374. https://doi.org/10.1007/s11060-012-0902-8

[97] Hader, W.J., Steinbok, P., Hukin, J. and Fryer, C. (2000) Intratumoral Therapy with Bleomycin for Cystic Craniopharyngiomas in Children. Pediatric Neurosurgery, 33, 211-218. https://doi.org/10.1159/000055955

[98] Cho, W.S., Kim, S.-K., Wang, K.-C., Phi, J.H. and Cho, B.-K. (2012) Vasculopathy after Intracystic Bleomycin Administration for a Recurrent Cystic Craniopharyngioma: Case Report. Journal of Neurosurgery: Pediatrics, 9, 394-399. https://doi.org/10.3171/2012.1.PEDS11437

[99] Savas, A., Erdem, A., Tun, K. and Kanpolat, Y. (2000) Fatal Toxic Effect of Bleomycin on Brain Tissue after Intracystic Chemotherapy for a Craniopharyngioma: Case Report. Neurosurgery, 46, 213-216. https://doi.org/10.1093/neurosurgery/46.1.213

[100] Jakacki, R.I., et al. (2000) Phase II Evaluation of Interferon-Alpha-2a for Progressive or Recurrent Craniopharyngiomas. Journal of Neurosurgery, 92, 255-260. https://doi.org/10.3171/jns.2000.92.2.0255

[101] Yeung, J.T., Pollack, I.F., Panigrahy, A. and Jakacki, R.I. (2012) Pegylated Interferon-Alpha-2b for Children with Recurrent Craniopharyngioma. Journal of Neurosurgery. Pediatrics, 10, 498-503. https://doi.org/10.3171/2012.9.PEDS12225

[102] Aylwin, S.J., Bodi, I. and Beaney, R. (2016) Pronounced Response of Papillary Craniopharyngioma to Treatment with Vemurafenib, a BRAF Inhibitor. Pituitary, 19, 544-546. https://doi.org/10.1007/s11102-015-0663-4

[103] Li, Q., et al. (2013) All-Trans Retinoic Acid Inhibits Craniopharyngioma Cell Growth: Study on an Explant Cell Model. Journal of Neuro-Oncology, 112, 355-364. https://doi.org/10.1007/s11060-013-1080-Z

[104] Gump, J.M., et al. (2015) Identification of Targets for Rational Pharmacological Therapy in Childhood Craniopharyngioma. Acta Neuropathologica Communications, 3, 30. https://doi.org/10.1186/s40478-015-0211-5

[105] Uto, M., Mizowaki, T., Ogura, K. and Hiraoka, M. (2016) Non-Coplanar Volumetric-Modulated Arc Therapy (VMAT) for Craniopharyngiomas Reduces Radiation Doses to the Bilateral Hippocampus: A Planning Study Comparing Dynamic Conformal Arc Therapy, Coplanar VMAT, and Non-Coplanar VMAT. Radiation Oncology, 11, 86. https://doi.org/10.1186/s13014-016-0659-x 


\section{List of Abbreviations}

CP Craniopharyngioma

ACP Adamantinoumatous Craniopharyngioma

PCP Papillary Craniopharyngioma

RCP Craniopharyngioma

CT Computed Tomography

MRI magnetic Resonance Imaging

GTR Gross Total Resection

STR Subtotal Resection

RT Radiation Therapy

GKS Gamma Knife Surgery

SRS Stereotactic Radiosurgery

RR Recurrence Rate

RCTs Randomized Control Trials

GHRT Growth Hormone Replacement Therapy

H.E Hematoxylin and Eosin Staining 